\title{
LAS RELACIONES INTERNACIONALES ENTRE MÉXICO Y VENEZUELA. ENCUENTROS Y DESENCUENTROS
}

\author{
Guadalupe VAUTRAVERS TOSCA*
}

RESUMEN: Las relaciones bilaterales entre México y Venezuela, desde que ambos nacieron a la vida independiente, han sido, con algunas excepciones, cordiales y de apoyo mutuo. Durante dichas relaciones, se destaca la participación de los dos países en organismos regionales multilaterales y tratados bilaterales de cooperación para el desarrollo de las naciones menos adelantadas de la región y, sobre todo, acuerdos encaminados a la solución pacífica de controversias en nuestro continente y en el mundo en general. Aunque no es fácil entender los enfrentamientos verbales entre el ex presidente Vicente Fox y el presidente Hugo Chávez, ni las declaraciones de los cancilleres y diplomáticos de ambos países, encontramos que tal situación ofensiva entre gobernantes y diplomáticos de los dos Estados, ya se había presentado durante el siglo XX.

ABSTRACT: The bilateral relations between Mexico and Venezuela, since both were born to the independent life, have been, with some exceptions, warm and of mutual support. During these relations, emphasizes the participation of this two countries in multilateral regional organisms and bilateral treaties of cooperation for the development of the less advanced nations in the region and, mainly, agreements directed to the pacific solution of controversies in our continent and the world in general. Although it is not easy to understand the verbal confrontations between ex-president Vicente Fox and the President Hugo Chavez, nor the declarations of the chancellors and diplomats of both countries, we found that such offensive situation between governors and diplomats of both States already had appeared during XX century.

RÉSUMÉ: Les relations bilatérales entre le Mexique et le Venezuela, puisque tous les deux ont été soutenus à la vie indépendante, ont été, à quelques exceptions, chaudes et d'appui mutuel. Pendant ces relations, souligne la participation du ce deux pays dans les organisations régionales multilatérales et les traités bilatéraux de la coopération pour le développement des nations moins avancées dans la région et, principalement, les accords dirigés vers la solution Pacifique des polémiques dans notre continent et le monde en général. Bien qu'il ne soit pas facile de comprendre les confrontations verbales entre le ex Président Vicente Fox et le Président Hugo Chavez, ni les déclarations des chanceliers et des diplomates des deux pays, nous avons constaté qu'une telle situation blessante entre les gouverneurs et les diplomates des deux états, déjà apparue pendant le siècle $X X$.

* Profesora de Derecho internacional público y de Tratados internacionales en la Universidad Juárez Autónoma de Tabasco (UJAT) y miembro del Sistema Nacional de Investigadores. 
SUMARIO: I. Introducción. II. Independencia de México y Venezuela. III. Encuentros. IV. Desencuentros. V. Conclusiones.

VI. Bibliografía.

\section{INTRODUCCIÓN}

El presente texto se refiere a la política exterior que nuestro país ha mantenido con Venezuela, a partir de la independencia de ambos países, y constituye el tercero de los artículos publicados por quien esto suscribe con base en la investigación acerca de "La política exterior de México hacia los países del Caribe". Con anterioridad han aparecido estudios específicos respecto a las relaciones de nuestro país con Cuba, Estados Unidos de América y las islas del Caribe antillano. ${ }^{1}$

Las palabras clave aquí son encuentro, en la acepción de "entrevista entre dos o más personas, con el fin de resolver o preparar algún asunto", ${ }^{2}$ y desencuentro, como "encuentro fallido o decepcionante, desacuerdo, discordia". 3

La intención al abordar el tema de las relaciones diplomáticas entre México y Venezuela es puntualizar la postura de cooperación de ambos países a favor de nuestros vecinos latinoamericanos, ya que desde el inicio de su vida independiente coincidieron con el ideal de Simón Bolívar de una América unida y fuerte que pudiera enfrentar las intenciones colonizadoras de las potencias europeas y, posteriormente, las de Estados Unidos de América. ${ }^{4}$ Esta postura fue prácticamente permanente (con excepción de una ruptura de relaciones diplomáticas que duró casi 10 años) y se ha expresado en varios acuerdos internacionales como el Programa de Cooperación Energética para Países de Centroamérica y El Caribe, mejor conocido como el Acuerdo de San José, que ambas naciones fir-

1 Vautravers Tosca, Guadalupe, "Las transformaciones en la política exterior de México respecto de Cuba y los Estados Unidos de América. Análisis a la mitad del sexenio de Vicente Fox Quesada", Anuario Mexicano de Derecho Internacional V-2005, México, UNAM, Instituto de Investigaciones Jurídicas, 2005, pp. 611-630, e id., "La política exterior de México hacia los países del Caribe Antillano. Continuidad y cambio", El Caribe entre México y Estados Unidos, Morelia, Universidad Michoacana de San Nicolás de Hidalgo, Instituto de Investigaciones Históricas, 2005, pp. 225-253.

2 Real Academia Española, Diccionario de la lengua española, 22a. ed., Madrid, Espasa-Calpe, 2001, p. 906.

3 Ibidem, p. 779.

4 Secretaría de Relaciones Exteriores, Política exterior de México, 175 años de historia, México, Talleres Gráficos de la Nación, 1985, p. 32. 
maron el 3 de agosto de 1980, para promover la venta de petróleo a precios preferenciales a dichos países. ${ }^{5}$ Coincidieron también en el Consenso de Cartagena, el Grupo de Río y el Grupo de los Tres (acuerdo de cooperación económica que fue denunciado por el presidente de Venezuela Hugo Chávez y sólo continuará entre Colombia y México). Destaca de manera especial la participación de ambos gobiernos en el Grupo de Contadora, ${ }^{6}$ como mediadores en los conflictos suscitados en los países centroamericanos durante la década de los años ochenta.

Se hace también un análisis de los desencuentros que se han presentado en las relaciones diplomáticas entre nuestro país y Venezuela a partir del porfiriato, ya que el 4 de febrero de 1903, el entonces presidente de México instruyó a su embajador en Estados Unidos para que aprovechara el bloqueo que Alemania, Italia y Gran Bretaña habían impuesto a los puertos venezolanos a consecuencia de deudas contraídas con empresas europeas, y solicitara a Venezuela el pago de dieciocho mil libras esterlinas con los réditos correspondientes desde 1827, por concepto de un préstamo que hizo México a la Gran Colombia ${ }^{7}$ y que fue vendido a la compañía Casa Martínez del Río Hermanos. ${ }^{8}$

En el mismo orden de ideas, tenemos que en 1924 se dio la primera ruptura de relaciones diplomáticas entre los dos países. ${ }^{9}$ Este hecho tuvo como antecedente las declaraciones que hizo José Vasconcelos, entonces rector de la Universidad Nacional de México, quien en octubre de 1920 se refirió al presidente venezolano diciendo: "No debemos callar el hecho de que Juan Vicente Gómez es un cerdo humano que deshonra nuestra raza y deshonra a la humanidad". ${ }^{10}$ Agresión que dio lugar a múltiples

5 Presidencia de la República, "Se prorrogó el Acuerdo de San José”, Actividades de la Presidencia de la República, Los Pinos, 4 de agosto de 2004, www.tlatoani. 2004.presidencia.gob.mx/comunicados.

6 Flores Olea, Víctor, Relación de Contadora, México, Secretaría de Relaciones Exteriores-Fondo de Cultura Económica, 1988.

7 Unidad territorial bajo el dominio español que dio origen a las actuales repúblicas de Colombia, Ecuador y Venezuela.

8 Pérez Reyes, Elda, "Manuel Aspíroz ante el bloqueo de los puertos venezolanos (1902-1903)", El Caribe entre México y los Estados Unidos, México, Universidad Michoacana de San Nicolás de Hidalgo, Instituto de Investigaciones Históricas, 2005, p. 74.

9 López-Portillo Tostado, Felícitas, "La normalización de las relaciones con los países grancolombianos", Bajo el manto del Libertador. Colombia, Panamá y Venezuela 1821-2000, México, Secretaría de Relaciones Exteriores, 2004, pp. 104-111.

10 Ibidem, p. 104. 
declaraciones del presidente de Venezuela y del embajador de ese país ante Estados Unidos en contra del gobierno de México, aunque finalmente el 24 de julio de 1933, aniversario del natalicio de Simón Bolívar, fueron restablecidas las relaciones diplomáticas entre los dos países.

Después de estos incidentes, las relaciones bilaterales continuaron en forma amistosa y cordial hasta noviembre de 2005, cuando las confrontaciones entre los presidentes Hugo Chávez, de Venezuela, y Vicente Fox, de México, dieron lugar el retiro de sus respectivos embajadores. Actualmente las relaciones diplomáticas han mejorado, toda vez que se han nombrado nuevos embajadores en ambos países.

\section{INDEPENDENCIA DE MÉXICO Y VENEZUELA}

En 1821, México iniciaba su vida como país independiente y se veía precisado a consolidarse internamente como nación y a obtener el reconocimiento y respeto internacional; dos problemas fundamentales, aunque íntimamente relacionados, ya que la política interna y la política externa forman parte de un mismo proceso. Así, el siglo XIX representó para México su hechura como nación, el momento en que nuestro país dejó de ser objeto de la historia para ser sujeto de la misma. ${ }^{11}$

De igual forma, el nacimiento de la República de Venezuela en 1830 marcó, indiscutiblemente, el final de un periodo caracterizado por la lucha contra el poderío español y el anhelo de crear una república separada de la Gran Colombia, con lo cual, el proyecto de Simón Bolívar para evitar la fragmentación de las antiguas colonias hispanoamericanas quedó sólo como una utopía, ${ }^{12}$ ya que el fin de la Gran Colombia coincidió, prácticamente, con la muerte de este prócer ocurrida el 17 de diciembre de $1830 .{ }^{13}$

\section{ENCUENTROS}

El ideal de Simón Bolívar, "los gobiernos libres de la América del sur, unidos en la dependencia, ahora lo estarán en la libertad”, coincidía

11 Secretaría de Relaciones Exteriores, Política exterior de México..., cit., nota 4, p. 21.

12 Collado Herrera, María del Carmen, Venezuela, una historia breve, México, Instituto Mora, 2000, p. 52.

13 Idem. 
plenamente con la visión de los insurgentes mexicanos, quienes consideraban que "la lucha de México es la lucha de América". ${ }^{14}$

Para Miguel Hidalgo y sus colaboradores Ignacio Allende, José María Chico e Ignacio Rayón, entre otros, la alianza y la colaboración con los países del sur del continente se planteaba como una necesidad fundamental desde la Guerra de Independencia, ya que, después de diciembre de 1810, reconocieron que los Estados Unidos no brindarían ayuda material ni moral en favor de la independencia mexicana, ${ }^{15}$ toda vez que el espíritu práctico de aquella nación se hallaba tan cerca de México pero tan lejos a la vez, como advertía, con decepción y dolor, Bernardo Gutiérrez de Lara, quien había sido enviado por los insurgentes mexicanos para entrevistarse con James Monroe, secretario de Estado estadounidense. ${ }^{16}$

Este principio de solidaridad latinoamericana propugnado por México quedaba ya enunciado en un comunicado de Tadeo Ortiz, enviado por Rayón a las Provincias Unidas de Sudamérica, y del cual es imprescindible rescatar el siguiente concepto: "Si hubiera de haber alguna vez una alianza natural, íntima y permanente entre los pueblos, es la que se debe formar entre la América del Sur y México". ${ }^{17}$

Desde 1821, nuestro país contaba con una visión clara y perfectamente definida de lo que debían ser sus relaciones internacionales. En el dictamen presentado por la Comisión de Relaciones Exteriores a la Soberana Junta Gubernativa del Imperio Mejicano el 29 de diciembre de 1821, durante el Imperio de Agustín de Iturbide, ${ }^{18}$ se aprecia que lo prioritario era América Latina, sin embargo, el tema más importante era la relación con Estados Unidos. Mientras que en el trato con los gobiernos latinoamericanos se hacía énfasis en la cooperación y en la solidaridad,

14 Secretaría de Relaciones Exteriores, Política exterior de México..., cit., nota 4, p. 32 .

15 Experiencia de Bernardo N. Gutiérrez de Lara, enviado por los insurgentes mexicanos a entrevistarse con el secretario de Estado de EUA, James Monroe, citado por Carreño, Alberto María, La diplomacia extraordinaria entre México y Estados Unidos, México, Jus, 1951, p. 105.

16 Idem.

17 Secretaría de Relaciones Exteriores, Politica exterior de México..., cit., nota 4, p. 32 .

18 La Comisión la formaban Juan Francisco de Azcárate, el Conde de Casa de Heras y José Sánchez Enciso, y el objeto era ilustrar al gobierno de Agustín de Iturbide sobre las relaciones exteriores que debía tener el Imperio, por la naturaleza, por la dependencia y por la política. 
en las relaciones con los Estados Unidos era necesario reconocer su mayor fuerza, pero buscar la igualdad de trato, así como el respeto irrestricto hacia nuestra idiosincrasia que, por tener un origen histórico-cultural diferente, choca con la del país del norte. ${ }^{19}$

Los posteriores gobiernos de México continuaron defendiendo estos ideales y participaron en todos los proyectos de unión y concertación con América Latina desde el Congreso celebrado en Panamá en 1826. Fue en este tenor que Lucas Alamán recogía la herencia de Bolívar y al llegar nuevamente al Ministerio del Exterior, en 1831, determinó darle nueva vida a la idea anfictiónica, haciendo de la unión hispanoamericana el asunto preferente de la política exterior mexicana. Es así como, a partir de esta fecha y por doce años, México auspició un gran proyecto de unidad que debemos considerar eslabón indispensable para comprender la celebración del primer Congreso en Lima en 1847. ${ }^{20}$

El 8 de septiembre de 1835, llegó a México Francisco Michelena, que, al parecer, ya había sido cónsul de la Gran Colombia, y quien manifestó que desde dos años antes había sido nombrado para negociar en México un tratado en representación de Venezuela, que ya era soberana e independiente desde hacía un lustro, sin embargo, le había sido imposible presentarse antes, por lo que en esa fecha dio inicio a la encomienda que concluyó el 17 de agosto de 1836, cuando nombró vicecónsul a don Juan Nepomuceno de Pereda, para después ausentarse. En junio de 1837, el señor Pereda comunicó su promoción a la categoría de cónsul, misma que conservó hasta abril de 1842, cuando renunció a su cargo, y recobró la ciudadanía mexicana, quedando entonces encomendados los súbditos venezolanos, neogranadinos y ecuatorianos a los buenos oficios del pro-cónsul de su majestad británica. ${ }^{21}$

Al ocurrir la intervención francesa en México, el general José Antonio Páez, uno de los más destacados próceres de la Independencia de Venezuela que ya había estado aquí en 1854 y había sido condecorado con la Orden de Guadalupe, tuvo una reacción solidaria hacia nuestro país y manifestó a Matías Romero, embajador mexicano ante el gobierno de los

19 Secretaría de Relaciones Exteriores, Politica exterior de México..., cit., nota 4, p. 64.

20 Ibidem, pp. 84 y 85.

21 Méndez Reyes, Salvador, "De los antecedentes coloniales a la primera década del siglo XX”, en López-Portillo Tostado, Bajo el manto del Libertador..., cit., nota 9, pp. 88 y 89. 
Estados Unidos, "las más vivas simpatías por la causa de México" y se ofreció a luchar por la misma. Para ello, aseveró, pondría en dicho objeto "sus relaciones, sus recursos y su persona misma junto con otros militares que estaban en la mejor disposición de tomar partido contra los franceses". 22

Posteriormente, a raíz de una disputa de límites entre Venezuela y la Gran Bretaña, Porfirio Díaz en su informe al Congreso en 1896, respondió a lo expuesto por el secretario de Estado estadounidense Richard Olney de aplicar la Doctrina Monroe: "Cada república del hemisferio por medio de una declaración semejante a la del presidente Monroe, debería proclamar que todo ataque de cualquier potencia extraña, dirigido a menoscabar el territorio o la independencia, o cambiar las instituciones de una de las repúblicas americanas, sería considerado por la nación declarante como ofensa propia". 23

Texto que ha sido considerado pionero en la construcción del principio de defensa colectiva. El autor intelectual de la postura mexicana fue Ignacio Mariscal, secretario de Relaciones Exteriores del porfiriato durante 27 años. ${ }^{24}$

Así continuaron las relaciones cordiales entre nuestro país y Venezuela, hasta que se suspendieron en 1923 - como expondremos en el siguiente apartado-, y fueron restauradas el día 24 de junio de 1933, en el aniversario del natalicio de Simón Bolívar. Tres años más tarde, la Legación mexicana en Caracas fue elevada a la categoría de embajada. ${ }^{25}$

El 5 de abril de 1941, los gobiernos de Venezuela y Colombia solucionaron un largo litigio fronterizo iniciado en 1833 al firmar el Tratado de Demarcación de Fronteras y Navegación de los Ríos Comunes, ocasión que aprovechó el presidente mexicano Manuel Ávila Camacho (1940-1946) para enviar a sus pares un telegrama en donde expresaba su satisfacción por la actitud de ambos países: "con motivo [del] trascendental acuerdo [de] límites entre ese país y Venezuela que contrasta por sus formas pacíficas con actos de inaudita violencia empleados actual-

22 Ibidem, p. 91.

23 Ibidem, pp. 90 у 92.

24 Ibidem, p. 92.

25 López-Portillo Tostado, Felícitas, Bajo el manto libertador..., cit., nota 9, p. 111. 
mente por otros gobiernos y que demuestra espíritu [de] fraternidad [entre los] países contratantes". ${ }^{26}$

Dentro de este contexto, en la primavera de 1944, llegó a Caracas el general Juan F. Azcárate, que fue enviado especial del presidente Manuel Ávila Camacho, para servir de "enlace cultural" y de "acercamiento espiritual y fraternal entre México y los países hermanos". Con tal propósito, Azcárate realizó la exhibición de un material fílmico que difundía los logros de la Revolución mexicana en todos los aspectos, pero especialmente los beneficios sociales y culturales. A dicha reunión asistieron las principales personalidades políticas venezolanas, así como el cuerpo diplomático acreditado en la capital. ${ }^{27}$

Posteriormente, el 18 de octubre de 1945, el presidente de Venezuela, general Isaías Medina Angarita, fue derrocado por una coalición formada por militantes del Partido Acción Democrática junto con un grupo de jóvenes militares que se hallaban descontentos porque la bonanza petrolera no había alcanzado a su institución. Se estableció entonces una Junta Revolucionaria de Gobierno compuesta de siete miembros y encabezada por Rómulo Betancourt, quien envió telegramas a todos los países con los que Venezuela mantenía relaciones, para informar que la finalidad del golpe de Estado tenía por objeto: "presidir la convocatoria de un Constituyente para hacer una Constitución democrática que permitiera al país elegir libremente por sufragio universal, directo y secreto presidente de la República, para terminar con los gobiernos de facto legalizados que han sido por largos años la desvergüenza de nuestro país". ${ }^{28}$

Fiel a la Doctrina Estrada, México se abstuvo de calificar el cambio de gobierno en Venezuela, y las relaciones prosiguieron normalmente, aunque hubo cautela en torno al tema. ${ }^{29}$

Ya como presidente de Venezuela, Rómulo Betancourt visitó la ciudad de México en julio de 1946, durante el gobierno de Miguel Alemán. En esta misma fecha, el canciller mexicano Francisco Castillo Nájera dirigió al nuevo embajador de Venezuela en nuestro país, un comunicado oficial en el que recalcaba que "las relaciones con Venezuela son de enorme interés para México, dada su importancia histórica e influencia 
moral en Sudamérica"; además, el hermano país era rico e importaba casi todo lo que consumía, situación que le abría a México posibilidades insospechadas. ${ }^{30}$

La posición del gobierno mexicano frente a Venezuela, concretamente ante los golpes de Estado ocurridos en dicho país en 1945 y 1948, fue de acuerdo a los lineamientos de la Doctrina Estrada. Esto se hizo explícito cuando el embajador designado por la Junta Revolucionaria de Gobierno visitó al canciller mexicano Francisco Castillo Nájera para informarle que el nuevo gobierno venezolano cumpliría con todos los compromisos internacionales signados por su país, y solicitaba el reconocimiento de México, a lo cual, Castillo Nájera respondió que "conforme a la Doctrina Estrada, nuestro país seguiría manteniendo las cordiales relaciones de siempre con Venezuela". ${ }^{31}$

Entre 1948 y 1952, las relaciones diplomáticas de México con el gobierno militar venezolano fueron cordiales, al grado de que en septiembre de 1952, en vísperas de terminar el sexenio alemanista, se condecoró a los integrantes de la Junta Militar con el Águila Azteca, y en su último informe de gobierno, el presidente Miguel Alemán aseguró que: “Con las repúblicas hermanas de América Latina nuestras relaciones son especialmente cordiales; y ello se ha puesto de manifiesto en numerosas ocasiones". 32

Ya durante el gobierno encabezado por Adolfo Ruiz Cortines (1952-1958), se evidenció en México cierta frialdad hacia el gobierno militar venezolano, que a lo largo de esos años consolidó su vocación represora y antidemocrática. Aunque en apariencia las relaciones prosiguieron normalmente, en las Memorias de la Secretaría de Relaciones Exteriores no hay indicios de que hayan continuado las conversaciones iniciadas por el gobierno anterior para firmar un acuerdo comercial entre ambos países. ${ }^{33}$

30 López-Portillo Tostado, Felícitas, "Venezuela desde la Cancillería Mexicana: los años de la posguerra", Latinoamérica, Anuario de Estudios Latinoamericanos, México, UNAM, Centro Coordinador y Difusor de Estudios Latinoamericanos, núm. 30, 1998, pp. 188-190.

31 Ibidem, pp. 195 y 196.

32 López-Portillo Tostado, Felícitas, Bajo el manto del Libertador..., cit., nota 9, p. 160 .

33 Ibidem, p. 163. 
Posteriormente, México apoyó a Venezuela en la querella que este país entabló contra República Dominicana por el atentado al presidente Rómulo Betancourt en junio de 1960 (complot auspiciado por el dictador Trujillo), con la aclaración de que, independientemente de que en la isla antillana gobernara una dictadura, se trató de "una conspiración contra el Estado venezolano con objeto de subvertir el orden establecido e imponer, por la violencia, un cambio en la estructura política que el pueblo venezolano se ha dado en uso de sus derechos soberanos", según declaró el canciller mexicano Manuel Tello. ${ }^{34}$

Adolfo López Mateos fue el primer presidente mexicano que visitó América del Sur. El recorrido que realizó durante los dos primeros meses de 1960, tenía la intención de que las relaciones de México con estos países cambiaran el carácter simbólico que hasta entonces habían mantenido, y se propiciara un mejor escenario para la cooperación, por lo que México ingresó a la Asociación Latinoamericana de Libre Comercio (ALALC), y se acordó con Venezuela la cooperación en el caso del petróleo, carbón y hierro. En 1963, el presidente venezolano Rómulo Betancourt hizo una breve visita a México para refrendar los esfuerzos de colaboración y fue recibido con una "apoteósica" bienvenida por miles de trabajadores y con "el cielo nublado de papelillos de colores". ${ }^{35}$

En 1964, al finalizar el mandato de Adolfo López Mateos, México afrontó una situación difícil ante la petición que hizo Venezuela, en la IX Reunión de Cancilleres de la Organización de Estados Americanos, de reclamar a Cuba por los actos subversivos que los ciudadanos de esta isla habían hecho en su contra, actos que estimó "lesivos a la integridad territorial y a la soberanía de su país". México, fiel a sus principios y doctrinas, se opuso a las sanciones propuestas. ${ }^{36}$ De esta manera, con la consigna de no permitir que "circunstancias pasajeras" obstaculizaran las buenas relaciones con sus hermanas latinoamericanas, México imprimió un sello a su actuación política en el ámbito exterior $\mathrm{y}$, a diferencia de otros países, mantuvo relaciones con Cuba, por lo que asumió la repre-

34 Idem.

35 Muñoz Mata, Laura, “De la retórica al 'fortalecimiento de lazos'. En busca de la cooperación 1960-2000”, en López-Portillo Tostado, Felícitas, Bajo el manto del Libertador..., cit., nota 9, pp. 193 y 194.

36 Ibidem, pp. 195 y 196. 
sentación de los intereses de la isla en Panamá y en Colombia, y los de estos dos países y de Venezuela con la Gran Antilla. ${ }^{37}$

Durante el sexenio de Gustavo Díaz Ordaz (1964-1970), la tónica general de la política exterior mexicana estuvo marcada por una mayor preocupación por los problemas del desarrollo y las opciones para lograr mejores términos de intercambio, así como por el proceso de desarme. En el ámbito de las relaciones multilaterales, en diciembre de 1969 se firmó el Protocolo de Caracas, acuerdo que ampliaba el plazo para la formación de la zona de libre comercio. Si bien en los años sesenta México abandonó paulatinamente su anterior aislacionismo y empezó a abrirse al mundo, también mantuvo claramente la defensa de los grandes principios jurídico-políticos tradicionales que habían caracterizado a su política exterior. ${ }^{38}$

A los pocos meses de iniciado el periodo presidencial de Luis Echeverría Álvarez (1970-1976), se planteó la necesidad de buscar nuevos mercados y capitales para fortalecer la economía nacional y fomentar las exportaciones a fin de ampliar el margen de independencia económica frente a Estados Unidos. En este marco, se explican las relaciones con América Latina, tanto en el campo de los vínculos bilaterales como en el de los multilaterales, sobre todo a través de la Conferencia de las Naciones Unidas sobre Comercio y Desarrollo, la Asociación Latinoamericana de Libre Comercio y el Pacto Andino, organismos de carácter económico. Con estas acciones, México se convirtió en un promotor de la integración regional y subregional, ya que el gobierno mexicano buscaba la unión entre los países latinoamericanos.

Al mismo tiempo que la política exterior de México se orientaba a otros ámbitos y adquiría nuevos ritmos, se continuaba atendiendo aquellos temas que antes habían ocupado la agenda. Tal es el caso de la desnuclearización militar de América Latina, razón por la cual se siguieron realizando las sesiones del Organismo para la Proscripción de las Armas Nucleares en América Latina y el Caribe (OPANAL). ${ }^{39}$

En 1970, se estableció la Comisión Económica Bilateral México-Venezuela, en donde se examinó la posición de ambos países respecto a los asuntos de la ALALC, y la posibilidad de realizar inversiones mixtas en 
empresas industriales de interés común. También se abordó el tema de las comunicaciones y transportes, y se analizaron los vínculos diplomáticos con otras naciones. Asimismo, en un gesto de apoyo, México intervino como negociador en las pláticas con los secuestradores de un avión venezolano, quienes, después de que se resolvió el conflicto, pudieron dirigirse a Cuba. ${ }^{40}$

En 1974, a raíz de la llegada de Carlos Andrés Pérez a la presidencia de Venezuela (1974-1979), se creó entre este país y México una Comisión Económica Mixta y se firmaron varios convenios para proporcionar insumos a la corporación venezolana de petróleo, tanto en materia siderúrgica y cooperación técnica, como en aspectos culturales. Entre estos tratados, se signó uno para establecer un programa de intercambio de jóvenes técnicos, y otro para compartir conocimientos y experiencia en transferencia de tecnología. Además de las relaciones bilaterales, ambas naciones trabajaron en el Grupo de Países Latinoamericanos y del Caribe Exportadores de Azúcar (Geplacea), en la Organización Latinoamericana de Energía (Olade) y en el Pacto de Cartagena, donde se suscribió la Comisión México-Andina con la participación de Colombia, Venezuela, Perú, Bolivia, Chile y Ecuador, a fin de incrementar el intercambio entre ellos. De igual forma, Venezuela apoyó las tesis y propuestas que formuló el presidente mexicano Luis Echeverría para que el Pacto Andino fuera un organismo exclusivamente latinoamericano, asimismo, estuvo de acuerdo con la Carta de Derechos y Deberes Económicos de los Estados, que México presentó ante la Asamblea General de las Naciones Unidas, y con la propuesta que hizo ante la III Conferencia de las Naciones Unidas sobre el Derecho del Mar, respecto a los derechos de los países con litorales marítimos. ${ }^{41}$

Durante estos mismos gobiernos y en iniciativa conjunta, México y Venezuela alentaron la creación del Sistema Económico Latinoamericano (Sela). Este nuevo mecanismo de cooperación regional marcó el papel de ambos países como "potencias emergentes" de la región. De igual forma, estuvieron interesados en la reforma de los estatutos de la Organización de los Estados Americanos y en la creación de la Empresa Naviera Multinacional que fue constituida a finales de mayo de 1975, por medio de un documento suscrito en San José de Costa Rica y donde también 
participaron Colombia, Venezuela, Costa Rica, Cuba, Jamaica, Nicaragua y Panamá. ${ }^{42}$

Durante el sexenio de Luis Echeverría Álvarez no todo fue política y economía, también se otorgó un espacio importante a la "diplomacia cultural", con la visita de la señora María Esther Zuno de Echeverría a varios países, entre ellos Venezuela y Panamá. ${ }^{43}$

Encuentros en las últimas décadas del siglo XX

\section{A. Tratados del Canal de Panamá}

México y Venezuela también coincidieron cuando sus respectivos presidentes, José López Portillo y Carlos Andrés Pérez, junto con los mandatarios de Colombia, Jamaica y Costa Rica, formaron parte del grupo de países que fungieron como testigos en las negociaciones para los Tratados del Canal de Panamá en $1977 .{ }^{44}$

\section{B. Acuerdo de San José o Acuerdo Petrolero de San José}

Dentro de los encuentros entre México y Venezuela, tenemos el acuerdo para suministrar petróleo crudo a los países centroamericanos y caribeños en condiciones financieras ventajosas para los usuarios, a través del Programa de Cooperación Energética para países de Centroamérica y el Caribe, conocido como Acuerdo de San José ${ }^{5}$ o Acuerdo Petrolero de San José. ${ }^{46}$ Este convenio entró en vigor el 3 de agosto de 1980 y fue renovado durante 25 años, toda vez que a partir de noviembre de 2005, se inició una serie de desavenencias entre los jefes de Estado de ambos países, que apenas parecen resolverse.

La idea de dicho programa surgió a raíz de la petición del entonces presidente de Costa Rica, Rodrigo Carazo, para que México y Venezuela, los principales exportadores de petróleo de América Latina, trataran de aliviar la crítica situación económica de los países de la Cuenca del

42 Ibidem, p. 208.

43 Ibidem, p. 210.

44 Ibidem, p. 213.

45 Ibidem, p. 211.

46 Secretaría de Relaciones Exteriores, Política exterior de México. 175 años de historia, México, Talleres Gráficos de la Nación, 1985, t. III, p. 369. 
Caribe mediante la seguridad del suministro de crudo con ciertas facilidades financieras, aunque ya desde 1974, Venezuela había puesto en vigor un mecanismo para vender petróleo a los países de Centroamérica en condiciones ventajosas. ${ }^{47}$

Cuando se decidió implementar el Acuerdo de San José, la economía de los países de Centroamérica pasaba por una situación crítica y desde entonces se ha seguido deteriorando, puesto que ninguno de ellos (con la excepción de Guatemala), cuenta con recursos petroleros propios. Por tanto, la compra de petróleo y sus derivados ha constituido una pesada carga para la pequeña economía agro exportadora de estas naciones. Así, por ejemplo, en 1979 Costa Rica, Guatemala y El Salvador tuvieron que dedicarle respectivamente el 16, 18 y $11.5 \%$ de su producto interno bruto. En 1981, Costa Rica dedicó el 22\% de las divisas que obtuvo mediante exportaciones para pagar sus importaciones de petróleo, y Nicaragua, el 37.6\%. De tal suerte, la deuda externa de los países en su conjunto casi se sextuplicó entre 1970 y 1978, por lo que, lógicamente, se convirtió en una carga cada vez más pesada, hasta llegar al extremo, en el caso de Costa Rica, de que el país tuviera que declarar una moratoria en septiembre de 1981.48

Como quedó estipulado en la declaración constitutiva, el Programa de Cooperación Energética para Países de Centroamérica y el Caribe tiene como propósito "atender el consumo interno neto petrolero de origen importado de los países del área y contribuir al financiamiento oficial correspondiente". Para ello, México y Venezuela se comprometieron a destinar, en partes iguales, hasta 160 mil barriles de petróleo al día, y acordaron otorgar crédito a los países beneficiarios "por el 30\% de sus respectivas facturas petroleras con un plazo de cinco años y una tasa de interés del $4 \% " .49$

Además de otorgar financiamiento a los países beneficiarios con esas condiciones preferenciales (lo cual de por sí es muy atractivo, puesto que actualmente la tasa prevaleciente en el mercado es de alrededor del $15 \%$ ), el programa considera la posibilidad de convertir dichos créditos en otros "de hasta 20 años con una tasa de interés anual del $2 \%$ ", si los

47 Idem.

48 Ibidem, p. 370.

49 Declaración conjunta de los presidentes de Venezuela y México, San José de Costa Rica, 3 de agosto de 1980. 
recursos "se destinan a proyectos prioritarios de desarrollo económico, en particular, aquellos relacionados con el sector de energía". ${ }^{50}$

Desde un principio se le atribuyó mucha importancia a este acuerdo, por tratarse, según se afirmaba, del "primer paso hacia un programa mundial de energía, y un modelo que puede ser aplicado a otros tipos de intercambio internacional", pues se sostenía que la concepción militar de la seguridad debía "ser sustituida por una concepción equitativa y dinámica de la cooperación económica. Frente a la alternativa absurda de la violencia; la racional de la cooperación". ${ }^{51}$

Los países beneficiarios de dicho instrumento fueron Costa Rica, El Salvador, Guatemala, Honduras, Nicaragua, Jamaica, Panamá y República Dominicana, además de Belice y Haití, que se incluyeron en 1988 y 1991, respectivamente. A lo anterior, se agrega el caso de Barbados, cuyo suministro depende únicamente de Venezuela. En tanto que, a principio de los años noventa, Panamá quedó sin acceso a los beneficios del acuerdo, debido al atraso en sus pagos. ${ }^{52}$

\section{Grupo de Contadora}

El 9 de enero de 1983, se reunieron en la Isla de Contadora, Panamá, los ministros de Relaciones Exteriores o cancilleres, Rodrigo Lloreda Caicedo, de Colombia; Bernardo Sepúlveda Amor, de México; Juan José Amado, de Panamá, y José Alberto Zambrano, de Venezuela, éste fue el día de la creación del Grupo de Contadora. En el mismo sentido, el 28 de julio de 1985, en la ciudad de Lima, Perú (en ocasión de la toma de protesta de Alán García como presidente de Perú), se reunieron los ministros de Relaciones Exteriores de Argentina, Brasil, Perú y Uruguay, Dante Caputo, Roberto Costa D'Abreu Sodre, Allan Wagner y Enrique Iglesias, respectivamente, con la finalidad de conformar el Grupo de Apoyo al Grupo de Contadora, toda vez que expresaron la disposición para integrar un mecanismo de apoyo permanente al esfuerzo de paz y cooperación promovido por el Grupo de Contadora en América Central, como parte de un sistema de concertación latinoamericana. ${ }^{53}$

50 Idem.

51 Muñoz Mata, Laura, op. cit., nota 35, p. 212.

52 Ibidem, pp. 212 y 213.

53 Flores Olea, Víctor, Relación..., cit., nota 6, pp. 21, 145 y 146. 
La creación del Grupo de Contadora, y posteriormente del Grupo de Apoyo, le permitieron al gobierno mexicano establecer alianzas, ampliar sus márgenes y ganar poder de negociación diplomática para avanzar en la solución a los problemas de la región centroamericana y lograr reinsertarla en el ámbito de la ley internacional. Se pretendía entonces proporcionar "un instrumento político basado en un proceso de consultas que condujera a la creación de condiciones pacíficas en el área", ante el gran temor de que la guerra en el istmo se generalizara. ${ }^{54}$

Según el canciller mexicano Bernardo Sepúlveda Amor, se perseguían tres objetivos: detener una conflagración bélica en el área; crear condiciones pacíficas para la región, mediante acuerdos destinados a eliminar el armamentismo y la presencia militar extranjera y, finalmente, impulsar un proceso de desarrollo económico y social. Tanto Contadora como su Grupo de Apoyo sostuvieron que los problemas latinoamericanos debían y podían ser resueltos por los mismos países latinoamericanos, posición en la que radicó gran parte de su importancia como órgano mediador. ${ }^{55}$ El Grupo de Apoyo evolucionó y se convirtió, en 1986, en el Grupo de los Ocho o Grupo de Río, al que nos referiremos en el apartado siguiente.

El mismo Sepúlveda Amor, como secretario de Relaciones Exteriores de México durante el sexenio de Miguel de la Madrid Hurtado, señalaba, respecto a la necesidad de crear el Grupo de Contadora, que "América Central ha vivido en los últimos años un tiempo de dificultad. Tres han sido sus aspiraciones no cumplidas: el desarrollo económico, el avance de las instituciones políticas y la eliminación de la violencia”.

Como se sabe, a principios del decenio de los ochenta, existía en América Central un marcado clima de confrontación, caracterizado por demostraciones de fuerza, avance de la carrera armamentista, actividades de desestabilización y ruptura del diálogo político; la posibilidad de que el conflicto se diseminara, se convertía aceleradamente en una amenaza para toda la región. Por tanto, la necesidad de conjurar el peligro fue una cuestión de interés y de seguridad nacional, inaplazable, para cada uno

54 Heller, Claude, "El Grupo de Contadora...", cit., nota 4, pp. 332-335.

55 Flores Olea, Víctor, op. cit., nota 6, pp. 216 y 217. 
de los países del istmo y para las naciones más cercanas a esa zona geográfica. ${ }^{56}$

Frente al riesgo de la regionalización incontrolable del conflicto, México, Colombia, Panamá y Venezuela tomaron la iniciativa para que los países centroamericanos llegaran a un acuerdo político por la vía de la negociación diplomática. ${ }^{57} \mathrm{Tal}$ iniciativa de buenos oficios y de mediación se sustentó siempre en la idea de un respeto escrupuloso del derecho internacional y de la identidad política de cada nación de América Central, y estaba aunada a la propuesta de estimular el desarrollo económico, social e institucional de los países del istmo.

Desde el inicio de sus gestiones, los países de Contadora estaban convencidos de que los conflictos que se desarrollaban en Centroamérica tenían su origen en las profundas carencias económicas y sociales de los países del área durante las últimas décadas. Frente a esta tesis, que se sustenta en una amplia experiencia histórica de las naciones latinoamericanas, se invoca, en ocasiones con una sospechosa vehemencia, que los enfrentamientos y procesos de cambio tienen su causa principal en factores relacionados con la confrontación entre el Este y el Oeste. ${ }^{58}$

En definitiva, podemos considerar que esta diferencia en las interpretaciones ha motivado las diversas conductas y estrategias políticas para tratar el conflicto centroamericano. El Grupo de Contadora y posteriormente el Grupo de Apoyo han sostenido invariablemente que un problema latinoamericano puede y debe ser resuelto por los propios países latinoamericanos. Esto significa, en otras palabras, que el conflicto en América Central tiene una raíz diferente a las pugnas políticas entre potencias y, por tanto, requiere de soluciones alejadas del trato militar que frecuentemente reciben los conflictos con vocación hegemónica. Tal en-

56 Sepúlveda Amor, Bernardo, "Presentación”, en Flores Olea, Víctor, op. cit., nota 6, p. 7.

57 Recordemos que dentro del derecho internacional se encuentran reconocidos como medios diplomáticos de solución pacífica de controversias: La negociación, los buenos oficios, la mediación, las comisiones de investigación y la conciliación, mismos que no son obligatorios para las partes en conflicto. Así también existen medios jurídicos de solución pacífica de controversias como son: El arbitraje y someter los litigios ante la Corte Internacional de Justicia (sólo asuntos entre Estados), cuyas resoluciones sí obligan a las partes en conflicto. Tenemos algunos ejemplos de litigios entre países de nuestro continente: Nicaragua vs. Estados Unidos de América y Honduras vs. El Salvador. Véase www.un.org/icj.

58 Sepúlveda Amor, Bernardo, op. cit., nota 56, pp. 7 y 8. 
foque ha tenido su expresión más positiva en la preocupación paralela de los grupos de Contadora y de Apoyo para que se canalicen los recursos provenientes, por cierto, no sólo de América Latina, al desarrollo económico de la región. 59

Bernardo Sepúlveda comentaba:

Debe decirse que los esfuerzos realizados en Centroamérica, durante más de cinco años, por México, Argentina, Brasil, Colombia, Panamá, Perú, Uruguay y Venezuela, constituyen un ejemplo único de concertación política regional entre varios gobiernos democráticos, toda vez que el proceso de consultas diplomáticas y de la negociación envuelto en el manto de Contadora recibió siempre un apoyo internacional ampliamente mayoritario. El prestigio de esta acción mediadora se consolidó rápidamente por su valor político intrínseco, pero también porque pronto se hizo evidente que se actuaba de una manera desinteresada y con respeto a la integridad política de cada una de las cinco naciones centroamericanas, sin afanes intervencionistas o hegemónicos. Repitió el ex canciller, que los grupos de Contadora y de Apoyo actuaron invariablemente con un propósito claro de encontrar soluciones equilibradas y respetuosas para todos los Estados de la región, sin excepciones de ninguna naturaleza. ${ }^{60}$

Al entonces presidente de México, Miguel de la Madrid Hurtado, le preocupaba la paz en Centroamérica, ya que en la reunión de los jefes de Estado de los países integrantes del Grupo de Contadora en Cancún, Quintana Roo, el 17 de julio de 1983, señaló: "Nuestro compromiso por la paz y el desarrollo del área es irrevocable. Seguiremos perseverando en nuestro esfuerzo. No omitiremos acción alguna y estoy cierto que esta actitud puede determinar la actualización de las partes involucradas directamente en el conflicto y de las interesadas en el desarrollo de los acontecimientos del área". ${ }^{61}$

59 Ibidem, p. 8.

60 Ibidem, pp. 8 y 9.

61 De la Madrid Hurtado, Miguel, "Palabras del presidente de los Estados Unidos Mexicanos al término de las segundas conversaciones con los presidentes de los países del Grupo de Contadora", Política Exterior de México, Discursos y documentos, México, Secretaría de Relaciones Exteriores, 1983, pp. 78 y 79. 


\section{Grupo de Río o Grupo de los Ocho}

El Grupo de Contadora y el Grupo de Apoyo evolucionaron para convertirse, en 1986, en el Grupo de los Ocho o Grupo de Río, que ha funcionado como un mecanismo latinoamericano de concertación política y un puente para el diálogo con otras regiones del mundo, particularmente con Europa. ${ }^{62}$

En diciembre de 1986, los cancilleres del Grupo de los Ocho se reunieron en Río de Janeiro y constituyeron el Mecanismo Permanente de Consulta y Concertación Política (Grupo de Río), para realizar consultas regulares como foro representativo de los intereses latinoamericanos ante otras comunidades internacionales. Sus objetivos básicos eran la ampliación y sistematización de la cooperación política entre los gobiernos integrantes; la concertación de posiciones comunes en los foros internacionales; la promoción del mejor funcionamiento y coordinación de los organismos latinoamericanos de cooperación e integración; la búsqueda de soluciones propias a los problemas y conflictos que afectan a la región, así como el impulso a los procesos de integración y cooperación, entre otros. ${ }^{63}$

El Grupo de Río pretendía cambiar la estructura económica para favorecer los intereses de los países en desarrollo, ya que consideraba necesario lograr un menor proteccionismo por parte de los países industrializados, mejorar las condiciones para la exportación y el rechazo al privilegio de la acción bilateral sobre la multilateral, además de crear un clima político más favorable en el ámbito internacional, y que los gobiernos y bancos acreedores reconocieran su corresponsabilidad en cuanto al problema de la deuda. ${ }^{64}$

Con Venezuela se actuó de común acuerdo a partir de opiniones que veían que "los conflictos y crecientes tensiones y las severas dificultades económicas que dominan el escenario internacional hacen aún más necesario que sus países, al igual que otras naciones de América Latina impulsen iniciativas y acciones que favorezcan el entendimiento político y la negociación económica global". ${ }^{65}$

63 Ibidem, p. 223.

64 Idem.

65 Ibidem, p. 220. 
De ahí que dos temas fundamentales en la relación bilateral hayan sido el petróleo y la crisis centroamericana. ${ }^{66}$

\section{E. Consenso de Cartagena}

Además de los ocho países latinoamericanos más endeudados (Argentina, Bolivia, Brasil, Chile, Ecuador, Perú, República Dominicana y Uruguay), México, Colombia y Venezuela participaron en la constitución del Consenso de Cartagena, que pretendía ser "un diálogo político entre deudores y acreedores destinado a resolver, en su conjunto y en sus múltiples ramificaciones, el endeudamiento externo, mediante la adopción de medidas inmediatas sin desestimar las soluciones de mayor alcance".

Precisamente, la importancia de la reunión de Cartagena, subrayó José Ángel Gurría, se debió a que no restringió el problema de la deuda a un asunto financiero, sino que le dio un enfoque político. ${ }^{67}$

Los cancilleres y ministros reunidos en esa ocasión propusieron, entre otras medidas, la adopción de aquellas que condujeran a la reducción de las tasas nominales y reales de interés en los mercados internacionales, la máxima reducción de los márgenes de intermediación, la puesta en práctica de mecanismos que atenuaran el impacto de las altas tasas de interés, y que no se comprometieran los ingresos provenientes de las exportaciones en las renegociaciones de la deuda externa más allá de porcentajes razonables. ${ }^{68}$

La plataforma definida por los participantes en el Consenso de Cartagena tuvo su expresión inicial en la primera reunión ministerial de los once países (21-22 de junio de 1984), y se desarrolló progresivamente en las siguientes dos reuniones realizadas en Mar del Plata (13-14 de septiembre de 1984) y Santo Domingo (7-8 de febrero de 1985).

Para presentar el planteamiento básico de los países de Cartagena, se distinguen los siguientes pronunciamientos: Corresponsabilidad entre deudores y acreedores; voluntad de cumplimiento de los compromisos de pago externos; diálogo político sobre el problema de la deuda; tratamiento caso por caso; simetría de ajuste; interrelación deuda-financiamien-

66 Ibidem, pp. 220 y 221.

67 Idem.

68 Ibidem, pp. 222 у 223. 
to-comercio; abatimiento de las tasas de interés, financiamiento compensatorio de las alzas en las tasas de interés; posposición de pago de intereses; introducción de nuevas características en las operaciones de renegociación; generalización de las características positivas de las operaciones de renegociación; complementación de las operaciones de renegociación; modificación de las regulaciones bancarias en los países acreedores y propuestas relativas a los organismos financieros multilaterales. ${ }^{69}$

Lo anterior tranquilizó a los gobiernos de los países acreedores, quienes, en un principio, habían pensado en el espectro del "Club de los deudores" y en la atribución de intenciones, poco menos que apocalípticas, a sus integrantes. Los planteamientos de los once países latinoamericanos fueron reconocidos como objetivos y razonables, por lo que se les concedió un alto grado de viabilidad. ${ }^{70}$

\section{F. Grupo de los Tres o G-3}

Gracias a la experiencia exitosa del Grupo de Río, en 1989 se impulsó la formación de otro organismo multilateral. En la ciudad de Guayana, Venezuela, los cancilleres de Colombia, México y el país anfitrión, propusieron dos objetivos básicos para el Triángulo de la Integración o Grupo de los Tres, que serían realizar nuevos esfuerzos dirigidos a la integración económica por ramas de actividad específicas en lo bilateral y trilateral, de ser posible; así como, consolidar y dar mayor efectividad a la cooperación económica, cultural, científica y técnica de los tres países hacia Centroamérica y El Caribe. El trabajo de ese grupo se ha realizado en tres niveles: presidencial, ministerial, viceministerial y de coordinadores nacionales. ${ }^{71}$

Inaugurado en octubre de 1990 como un grupo de consulta y de evaluación política sobre la situación regional, y en particular, de la coyuntura y el desarrollo centroamericanos, el grupo que constituyeron Colom-

69 Secretaría de Relaciones Exteriores, Politica Exterior de México..., cit., nota 4, t. IV, pp. 158-165.

70 Ibidem, p. 165.

71 Muñoz Mata, Laura, op. cit., nota 35, p. 229. 
bia, México y Venezuela, evolucionó rápidamente hacia mayores compromisos de cooperación e integración económica. ${ }^{72}$

En primera instancia, se constituyeron los grupos de negociación oficial de alto nivel en las áreas de energía y comercio, a las que luego se sumaron otros cinco grupos especializados respectivamente en finanzas, transporte y comunicaciones, cultura, turismo, y cooperación con Centroamérica y el Caribe. Durante las conversaciones, se acordó que el plazo para liberar totalmente el comercio entre los tres países y constituir una zona de libre comercio no debería ir más allá de 1995. ${ }^{73}$

Los trabajos de este grupo internacional continuaron sin mayor cambio hasta el domingo 21 de mayo de 2006, cuando el actual presidente de Venezuela, Hugo Chávez Frías, anunció formalmente la salida de su país del Grupo de los Tres (G-3), acuerdo comercial que también incluye a Colombia y México, bajo el argumento de "salvaguardar los intereses nacionales porque el tratado internacional está conformado bajo el esquema del más puro neoliberalismo". ${ }^{74}$

Acorde con lo anterior, estimamos que las relaciones bilaterales entre México y Venezuela, desde que ambos nacieron a la vida independiente, han sido, con algunas excepciones, cordiales y de apoyo mutuo. Durante dichas relaciones, se destaca la participación de los dos países en organismos regionales multilaterales y tratados bilaterales de cooperación para el desarrollo de las naciones menos adelantadas de la región y, sobre todo, acuerdos encaminados a la solución pacífica de controversias en nuestro continente y en el mundo en general.

Aunque no es fácil entender los enfrentamientos verbales entre el ex presidente Vicente Fox y el presidente Hugo Chávez, ni las declaraciones de los cancilleres y diplomáticos de ambos países, encontramos que tal situación ofensiva entre gobernantes y diplomáticos de los dos Estados ya se había presentado durante el siglo XX, tal como lo analizaremos a continuación.

72 Secretaría Permanente del Sela, La nueva etapa de la integración regional, México, Sistema Económico Latinoamericano-Fondo de Cultura Económica, 1992, p. 19.

73 Idem.

74 "Venezuela oficializa retiro del G-3", BBC Mundo.com, México, lunes 22 de mayo de 2006. 


\section{DESENCUENTROS}

El 8 de enero de 1842, Santa Anna (que recientemente había retomado el poder) nombró a Manuel Crescencio Rejón como su representante ante el Imperio de Brasil y las repúblicas del sur, con la finalidad de invitar a los gobernantes de aquellos países a la celebración de una asamblea americana. El enviado mexicano se estableció en Caracas, Venezuela, y en una comunicación enviada a su cancillería el 27 de octubre de 1842, señaló que:

Encontré oposición desde el primer momento. Ésta reside no sólo en la persona del general Páez, sino que es general en el gobierno. Las razones por las que Venezuela se opone al proyecto son los temores de que el general Santa Anna piense renovar en esta vez... las pretensiones que tuvo el general Bolívar, de dominar las nuevas naciones del continente, cuando concibió la idea de formar un congreso en que fuesen todas ellas representadas por sus respectivos delegados. El excesivo ejército que existe en México y la dictadura que allí campea no son tampoco para infundir confianza; suponen además, que el gobierno de nuestra república no promueve la confederación americana sino por la necesidad que tiene de los auxilios de las demás para volverse a hacer del territorio de Texas, que consideran perdido para México. ${ }^{75}$

De la nutrida correspondencia que Manuel Crescencio Rejón dirigió a su cancillería en los cinco meses que duró su encomienda, se desprende una triste odisea; Venezuela fue particularmente hostil para la misión del enviado. El regionalismo era el santo y seña de su política, y su sentido antibolivariano - con todas sus consecuencias, como era la violenta oposición a todo lo que fuera supranacional - había de mostrarse como un obstáculo insalvable. ${ }^{76}$

En otro orden de ideas, en 1902 Venezuela entró en una grave crisis económica y tuvo que declarar una moratoria de sus deudas con Alemania, Italia y Gran Bretaña, por lo cual, estas potencias bloquearon algunos de sus puertos como medida de presión, y Estados Unidos empezó a fungir como mediador entre Venezuela y los países acreedores. Sin em-

75 Secretaría de Relaciones Exteriores, Política exterior de México..., cit., nota 4, t. II, pp. 254 y 255.

76 Idem. 
bargo, como ya se comentó, el 4 de febrero de 1903, Porfirio Díaz, contrario a los principios de política exterior que había defendido, instruyó a su embajador en los Estados Unidos, para que aprovechara la coyuntura y solicitara de Venezuela el pago de una deuda de dieciocho mil libras esterlinas con réditos desde 1827, procedentes de un préstamo de México a la Gran Colombia vendido a una compañía privada: la Casa Martínez del Río Hermanos. ${ }^{77}$

\section{Ruptura de relaciones diplomáticas entre México y Venezuela}

Posteriormente, en el otoño de 1923, las relaciones diplomáticas entre México y la República de Venezuela se suspendieron a causa de un confuso incidente, cuando a un grupo de artistas mexicanos de la legua se les impidió desembarcar en La Guaira. Aunque la situación se hallaba tirante desde tiempo atrás, a causa de unas altisonantes declaraciones de José Vasconcelos, entonces rector de la Universidad Nacional y más tarde influyente secretario de Educación Pública, quien en esa ocasión casi tildó al presidente venezolano de caníbal. ${ }^{78}$

En aquel momento, Venezuela vivía bajo la dictadura personalista de Juan Vicente Gómez, caudillo andino que gobernó con mano férrea durante 27 años (1908-1935), de ahí que pronto surgieran discrepancias entre ese régimen y el emergente poder revolucionario mexicano. En octubre de 1920, en ocasión del Día de la Raza, el rector de la Universidad Nacional de México, José Vasconcelos, pronunció un furibundo discurso contra el presidente venezolano, en el cual aseguraba que la causa de los males que agobiaban a nuestra América, no era otra que la falta de libertad, pues las tiranías mantenían en el atraso a los pueblos de la región. A pesar del negro panorama, añadió, había esperanzas de que las cosas mejoraran, ya que en el año que corría habían caído dos dictaduras: la de Venustiano Carranza y la del guatemalteco Manuel Estrada Cabrera. Pero en Venezuela gobernaba todavía "el último de los tiranos de la América española, el más monstruoso, el más repugnante y el más despreciable de todos los déspotas que ha producido nuestra infortunada estirpe". Contundente, Vasconcelos aseveró: "No debemos callar el hecho 
de que Juan Vicente Gómez es un cerdo humano que deshonra nuestra raza y deshonra a la humanidad". ${ }^{79}$

El gobierno de México señaló de inmediato que la opinión de Vasconcelos no reflejaba la posición oficial del país y, por lo tanto, no se solidarizaba con tales declaraciones. Lo que menos querían era un conflicto con el país hermano, sin embargo, la gota que derramó el vaso fueron las tonantes declaraciones que hizo el doctor Pedro Manuel Arcaya, embajador venezolano ante Washington, quien injurió públicamente a México en una reunión de la Junta Directiva de la Unión Panamericana, donde nuestro país participaba por primera vez después de haber restablecido las relaciones diplomáticas con Estados Unidos. Dicho personaje se lanzó contra la propuesta de elegir a la ciudad de México como sede de un encuentro interamericano, diciendo que "el próximo congreso no debe reunirse en la capital mexicana porque ella es un refugio de criminales; las escuelas mexicanas son focos de rebelión y salvajismo. México carece de personalidad porque es un país de libertinos y bandidos". Agregó también que el secretario de Educación Pública, el filósofo Vasconcelos, no era más que un "archiconspirador" que incitaba al gobierno del general Obregón a promover un movimiento revolucionario en Venezuela, hecho que constituía una verdadera "guerra solapada" contra su país. ${ }^{80}$

A pesar del sigilo diplomático, el asunto se conoció públicamente. La prensa mexicana responsabilizó al funcionario venezolano de entorpecer los acercamientos de México con el buen vecino del norte, y lo acusó de haber confundido a sus oyentes "con la tribu que rodea a su amo". Los sucesos anteriores motivaron las agresivas declaraciones del presidente Juan Vicente Gómez: "Esos mexicanos son unos bandidos y no me quieren porque soy un hombre de orden, pero me es indiferente. Yo me sacrifico por servir a mi patria, porque sin mí, Venezuela sería un México". El dictador remató: "Mejor que el tal Obregón haya roto las relaciones, porque esos son unos corrompidos que corrompen todos los pueblos que tratan". ${ }^{81}$

El gobierno mexicano difundió su versión de los hechos a través de un comunicado que fue enviado a todas las representaciones acreditadas 105.

López Portillo, Felícitas, Bajo el manto del Libertador..., cit., nota 9, pp. 104 y

$80 \quad$ Ibidem, pp. 107 y 108.

81 Ibidem, p. 108. 
en Latinoamérica para que lo dieran a conocer a los medios de comunicación. En ella, se consideraba insatisfactoria la respuesta venezolana, según la cual no se había permitido el desembarco de un grupo de artistas mexicanos porque "existían razones especiales extraordinarias". Como no se dieron otras justificaciones, ni tampoco se alegaron medidas de inmigración ni sanidad, y como el gobierno de México no podía permitir que se diera a sus nacionales un trato discriminatorio, ordenó el cierre de su consulado en Caracas y retiró el exequatur de los cónsules venezolanos en la ciudad de México y Tampico, aunque se difundió que "El gobierno de México ha declarado que no tiene por esta causa ningún agravio con el pueblo venezolano, que continúa contando con la simpatía de México". 82

El 1o. de septiembre de 1924, el general Obregón informó al Congreso: "Por causas ya suficientemente conocidas y derivadas de descortesías y desigualdades de tratamiento para nuestros nacionales, fueron clausurados los consulados mexicanos en Venezuela". ${ }^{83}$

Casi una década después, el 24 de julio de 1933, aniversario del natalicio de Simón Bolívar, fueron restablecidas las relaciones con Venezuela. En México la noticia se presentó con un bajo perfil, con el claro propósito de que pasara inadvertida, pues la mala fama de Juan "Bisonte" Gómez era más que conocida. ${ }^{84}$

En el informe presidencial del 1o. de septiembre de 1933, el general Abelardo L. Rodríguez, declaró que:

A fin de intensificar los sentimientos de amistad que el pueblo y el gobierno mexicanos abrigan hacia los demás países, y con el fin de buscar, además, el apoyo moral necesario que nos permita cooperar autorizadamente en las altas empresas de conciliación y armonía internacionales, el Ejecutivo, actuando por encima de todo prejuicio, desde un plano superior de comprensión humana, reanudó las relaciones de México suspendidas en diversas épocas y por diferentes motivos con las Repúblicas hermanas de Nicaragua, Perú y Venezuela. ${ }^{85}$

82 Ibidem, pp. 108-110.

83 Ibidem, p. 110.

84 Ibidem, p. 111.

85 Citado al pie de página por López-Portillo Tostado, Felícitas, Bajo el manto del Libertador..., cit., nota 9, pp. 111 y 112 . 
Las relaciones de México con Venezuela, restablecidas en 1933, proseguían normalmente y sin contratiempos. Sin embargo, éstos empezaron a presentarse a partir del sexenio de Lázaro Cárdenas y sus medidas reformistas, acciones que no coincidían con el estático contexto de Venezuela, por lo que no fueron bien recibidas. Por ejemplo, en octubre de 1937 el encargado de negocios ad interin de nuestro país, Salvador Navarro Aceves, insistía en que los medios de comunicación venezolanos, especialmente el periódico La Esfera, no sólo habían continuado, sino que habían recrudecido su campaña insidiosa en contra de México, y reproducían las críticas de los medios mexicanos de comunicación que estaban inconformes con la obra del gobierno. En tanto que la cancillería instruyó al diplomático para que no emitiera declaraciones, puesto que "sería muy inoportuno que usted se propusiera desvirtuarlas directamente". 86

Posterior a este incidente, las relaciones entre México y Venezuela recobraron su cordialidad, tal como se ha referido en el apartado de encuentros, y siguieron así hasta llegar a los acontecimientos suscitados en noviembre de 2005, entre los gobiernos de ambos países.

Como recordamos, el conflicto entre Hugo Chávez, presidente de Venezuela y Vicente Fox, ex gobernante mexicano, se inició como consecuencia de la participación de ambos en la IV Cumbre de las Américas celebrada en Mar del Plata, Argentina, del 4 al 6 de noviembre de 2005. Después de la Cumbre, el presidente Fox, quien estaba molesto porque no se logró firmar el Tratado del Área de Libre Comercio de las Américas, acusó a Chávez de orquestar protestas contra el mandatario estadounidense George W. Bush y declaró que no hubo acuerdos sustanciales, porque el presidente Néstor Kirchner, anfitrión de la Cumbre, estaba más preocupado en cumplir con la opinión pública argentina que en lograr que la reunión fuera un éxito. A lo que Kirchner respondió que Fox debería ocuparse de los asuntos mexicanos, y que él se ocuparía de los argentinos. ${ }^{87}$

El miércoles 9 de noviembre de 2005, los cancilleres de Argentina y México intentaron dar por superado el roce diplomático. Los ministros "reconocieron que en la discusión de temas complejos, las democracias

86 Ibidem, pp. 129-131.

87 "Ahora es Chávez contra Fox", BBCmundo.com, sección América Latina, México, jueves 10 de noviembre de 2005. 
maduras tienen lugar para las diferencias, sin que esto altere el excelente nivel de una relación como la que caracteriza a nuestras naciones". ${ }^{88}$

En ese contexto, el presidente venezolano Hugo Chávez, durante un acto oficial en su país, el mismo 9 de noviembre de 2005, manifestó: "Da tristeza el entreguismo del presidente Fox, verdaderamente da tristeza", y añadió "Qué triste que un presidente de un pueblo como el pueblo mexicano se preste a ser un cachorro del imperio". 89

Desde luego, el presidente Chávez ha sido un férreo opositor al Acuerdo de Libre Comercio de las Américas (ALCA), toda vez que desde 2002, planteó dudas razonables sobre los tiempos pertinentes para estar en condiciones de abrir el comercio, refiriéndose a los "enemigos de la democracia", y la necesidad de consultar al Congreso de su país, o, incluso, realizar un referéndum sobre si firmar el acuerdo o no. ${ }^{90}$ De modo que en esta cuarta Cumbre de las Américas, se manifestó en contra de la iniciativa estadounidense, que fue apoyada por nuestro país, aunque Venezuela y los países del Mercosur (Argentina, Brasil, Paraguay y Uruguay) estuvieron en contra. ${ }^{91}$ Además, Hugo Chávez propuso una iniciativa denominada Alternativa Bolivariana para las Américas (Alba). ${ }^{92}$

Conviene también recordar que el presidente Hugo Chávez se ha propuesto consolidar la integración energética de América del Sur, que surge como un nuevo paradigma en esta materia, y que cuestiona la aplicación del neoliberalismo a ultranza en la región. ${ }^{93}$ Dentro de este nuevo

88 Idem. Muñoz Ríos, Patricia, "Cancilleres de México y Argentina se comprometen a limar diferencias", La Jornada, México, jueves 10 de noviembre de 2005, consultado en http://www.jornada.unam.mx/2005/11/10/politica.php.

89 Idem.

90 Cerutti Guldberg, Horacio, "La utopía americana en el siglo XXI. ¿Utopía de la unidad o mitos de la integración?", Latinoamérica. Anuario de Estudios Latinoamericanos, México, UNAM, Centro Coordinador y Difusor de Estudios Latinoamericanos, núm. 34, 2002, p. 29.

91 BBCmundo.com..., cit., nota 87.

92 Zaldúa, Josetxo y Botero, Jorge Enrique, "Acusa Caracas a Fox de 'agresión sin sentido"”, sección Política, La Jornada, México, martes 15 de noviembre de 2005, consultado en www.jornada.unam.mx/2005/11/15.

93 Vargas, María del Rocío, "La integración energética en América del Sur: la iniciativa de Petroamérica”, Latinoamérica, Revista de Estudios Latinoamericanos, México, UNAM, Centro Coordinador y Difusor de Estudios Latinoamericanos, núm. 40, 2005, pp. 265-287. 
consenso, está la idea de fortalecer a las empresas energéticas en un contexto de mercado, cuando ello sea del interés público.

Como parte de este proceso nació Petroamérica, por iniciativa venezolana, y ahora Petrosur que buscan la creación de una empresa multinacional para integrar a las empresas energéticas públicas líderes, tales como PDVESA, ENARSA y Petrobras, al mismo tiempo que la política petrolera internacional del presidente Hugo Chávez se dirige hacia Centro, Sudamérica y el Caribe, mediante acuerdos de cooperación energética que muestran una estrategia geopolítica más amplia correspondiente al proyecto bolivariano mismo. ${ }^{94}$

El 13 de noviembre de 2005, durante su programa dominical Aló Presidente, Hugo Chávez le dijo al presidente mexicano Vicente Fox: "No se meta conmigo, caballero, porque sale espinao", y otros comentarios como: "Lo que pasó es que Fox salió de la Cumbre sangrando por la herida" y "Lo que pasó allá, eso se hincha, compadre, eso no se queda así". ${ }^{95}$ Ante esto, casi de inmediato, la cancillería mexicana conminó a Caracas a presentar disculpas por lo que consideró falta de respeto del presidente Hugo Chávez hacia su par mexicano. ${ }^{96}$

La situación se volvía cada vez más tensa, y el 14 de noviembre de 2005 la prensa informaba: "Al borde de la ruptura de relaciones diplomáticas quedaron hoy los gobiernos de México y Venezuela, luego de que el canciller local, Alí Rodríguez, ordenó la retirada de su embajador en México, Vladimir Villegas". A media mañana, el alto funcionario venezolano declaró que "el ultimátum del presidente (Vicente) Fox es una agresión sin sentido", y remarcó que "esta situación es de entera responsabilidad del presidente Fox; no tiene justificación". De inmediato, las respectivas embajadas quedaban bajo la dirección de encargados de negocios, lo que, según explicó el canciller venezolano, "permitirán que sigamos trabajando para tratar de solucionar el problema". Pero hoy las relaciones "bajaron de nivel". Ese mismo día, el canciller venezolano difundió un comunicado dando a conocer la decisión de retirar al embajador destacado en México. "Nosotros damos por superado este problema, este desencuentro, no queremos la ruta de la confrontación. Pedimos

94 Idem.

95 Zaldúa, Josetxo y Botero, Jorge Enrique, op. cit., nota 92.

96 Idem. 
que se nos respete, nada más", dijo en una entrevista el canciller venezolano. ${ }^{97}$

Por su parte, el embajador mexicano acreditado ante Venezuela también regresó a nuestro país a solicitud de la Secretaría de Relaciones Exteriores, ya que el canciller mexicano Luis Ernesto Derbez hizo oficial la degradación de la relación bilateral con el retiro de embajadores de las dos sedes, poco antes de las seis de la tarde del lunes 14 de noviembre de $2005,{ }^{98}$ en los siguientes términos:

No obstante lo anterior, toda vez que las declaraciones del presidente de Venezuela atentan contra la dignidad del pueblo y gobierno mexicanos, México exige una disculpa formal del gobierno de Venezuela, en el transcurso del lunes 14 de noviembre. De no producirse esta disculpa, el gobierno de México procederá a pedir el retiro inmediato del embajador de Venezuela (Vladimir Villegas) y a llamar al representante de México en ese país (Enrique Loaeza Tovar), reduciendo el nivel de las relaciones al de encargados de negocios. ${ }^{99}$

En tanto que Luis Ernesto Derbez, secretario de Relaciones Exteriores, ratificaba: "Mientras el gobierno de Venezuela no ofrezca una disculpa formal por las declaraciones de Hugo Chávez en contra del presidente mexicano, Vicente Fox, las relaciones diplomáticas entre ambas naciones permanecerán a nivel de encargados de negocios". ${ }^{100}$

En una entrevista radiofónica, cuya versión fue difundida por la dependencia, el canciller insistió en que el ofrecimiento de disculpas era condición para que las relaciones diplomáticas retornaran al nivel de embajadores y superar la crisis por la que atravesaban en ese momento.

Aclaró también que, aún en el supuesto caso de que se presentaran excusas, el gobierno venezolano tendría que solicitar la acreditación o el beneplácito del gobierno de México para un nuevo embajador, pues al anterior, Vladimir Villegas, le había sido retirada, como explicó.

97 Idem.

98 Román, José Antonio y Petrich, Blanche, “¡Vente ya, hoy!, llamado de Caracas a su embajador", La Jornada, México, martes 15 de noviembre de 2005, consultado en www.jornada.unam.mx/2005/11/15.

99 Román, José Antonio, "Exige México a Chávez disculparse hoy mismo", La Jornada, México, lunes 14 de noviembre de 2005, consultado en www.jornada.unam . $m x / 2005 / 11 / 14$.

100 Idem. 
Dada la ofensa, lo que hemos puesto, digamos, como condición, no es solamente que se vaya su embajador, que es lo que ellos hicieron el lunes, sino que este embajador (Villegas) no puede regresar, y de hecho ninguna persona puede venir a usar o utilizar la embajada en ese cargo, a menos que el gobierno mexicano nuevamente proceda a dar un beneplácito, que es la práctica normal.

Y añadía: "así, mientras nuestro diplomático regresa por petición del gobierno mexicano y hasta el momento, en teoría, nuestro embajador podría regresar allá una vez que se normalizara la situación, ellos tendrían que acreditar a un nuevo representante". ${ }^{101}$

Pese a esta difícil situación, Derbez aclaró que no existía ruptura de relaciones, sino que éstas se mantenían en todos los niveles, tanto comerciales como de protección consular y culturales. "Yo esperaría - dijopor tanto, que en este momento la situación baje en cuanto a tensión y mantengamos un estado como el que en este momento tenemos, hasta en tanto no recibamos nosotros esta disculpa". ${ }^{102}$

Debido a que también el presidente Vicente Fox emitía declaraciones contra los opositores a un área de libre comercio en el continente, el miércoles 16 de noviembre de 2005, en un programa televisivo, el presidente Hugo Chávez manifestó: "El gobierno foxista es aliado del imperio". ${ }^{103}$

No hubo más acercamientos entre el ex presidente Vicente Fox y el presidente venezolano Hugo Chávez; por el contrario, el domingo 21 de mayo de 2006, en su programa semanal de televisión Aló Presidente, el mandatario de Venezuela anunció formalmente la salida de su país del Grupo de los Tres (G-3), acuerdo comercial que también incluye a Colombia y México, con el argumento de que el organismo fue conformado bajo el esquema del más puro neoliberalismo. ${ }^{104}$

A partir de la toma de posesión de Felipe Calderón como nuevo presidente de nuestro país, se presentó un incidente respecto de las declara-

101 “Chávez debe ofrecer disculpas, insiste Derbez”, La Jornada, México, miércoles 16 de noviembre de 2005, consultado en www.jornada.unam.mx/2005/11/16.

102 Idem.

103 Zaldúa, Josetxo, "El gobierno foxista es aliado del imperio, arremete de nuevo Chávez", La Jornada, México, jueves 17 de noviembre de 2005, consultado en www.jor nada.unam. $m x / 2005 / 11 / 17$.

104 "Venezuela oficializa retiro del G-3", op. cit., nota 74. 
ciones vertidas por éste en el Foro Económico Mundial de Davos, Suiza, ya que criticó las políticas económicas de Venezuela, Argentina y Bolivia, a lo que Hugo Chávez le respondió el 27 de enero de 2007 lo siguiente: "Señor presidente de México, si quiere que lo respeten, respete, ¿oyó camarita?", ${ }^{105}$ posterior a esta desavenencia no se han presentado incidentes mayores entre ambos gobernantes.

En una entrevista publicada el 3 de junio de 2007, Felipe Calderón manifestó que México trabaja "sin prisas pero sin pausas" para recomponer sus relaciones con Venezuela y Cuba, sin que esto signifique "voltear la mirada a otro lado" cuando en algún país del mundo se vulneren principios fundamentales. ${ }^{106}$

En julio de 2007 se presentaron algunos rumores respecto a que se había nombrado al nuevo embajador de Venezuela en México, pero, la ministra encargada de negocios de la embajada de Venezuela, Dalia Eloísa Lagonell, informó que todavía "no hay nada oficial" sobre la normalización de las relaciones diplomáticas entre el gobierno de ese país y México, que desde 2005 están en su mínimo nivel, tras varios desencuentros entre los presidentes Hugo Chávez y Vicente Fox. ${ }^{107}$

Hasta agosto de 2007, las relaciones entre México y Venezuela han mejorado en forma notable, toda vez que ambos gobiernos designaron nuevos embajadores, Jesús Mario Chacón por parte de México, ${ }^{108}$ y Roy Chaderton Matos de Venezuela. ${ }^{109}$

A lo largo de la presente investigación reseñamos las buenas relaciones que durante casi dos siglos han mantenido los gobiernos de México y Venezuela, así también, dimos cuenta de las contadas ocasiones en las que ambos países tuvieron desavenencias, y de la única vez que se llegó a la ruptura de relaciones diplomáticas en septiembre de 1924, antes de

105 Gobierno Bolivariano de Venezuela, Venezuela exige Respeto a su Soberanía al Presidente de México Felipe Calderón, Caracas, Ministerio del Poder Popular para la Comunicación y la Información, 28 de enero de 2007.

106 Ramírez Domínguez, Kenneth, "Felipe Calderón confía en que relaciones diplomáticas con Cuba y Venezuela se normalizarán", El Universal on line, México, 3 de junio de 2007.

107 Román, José Antonio, "Nada oficial sobre normalización de relaciones con México: Lagonell”, La Jornada, México, miércoles 11 de julio de 2007.

108 "México designa a su nuevo embajador en Venezuela", La Jornada, México, 9 de agosto de 2007, consultado en www.lajornada.unam.mx.

109 "Nombran nuevo embajador de Venezuela en México", Terra, 7 de agosto de 2007, consultado en www.terra.com.mx/politica. 
los sucesos de noviembre de 2005, cuando dichas relaciones llegaron al nivel más bajo.

No queremos dejar de comentar los principios normativos de la política exterior del gobierno mexicano, que fueron elevados a rango constitucional el 11 de mayo de $1988,{ }^{110}$ mismos que se encuentran establecidos en el artículo 89, fracción X, de la Constitución, los cuales deben ser cumplidos por el presidente de la República en sus relaciones internacionales, además de que esos principios habían sido aprobados por los miembros de las Naciones Unidas y de los Estados Americanos en sus cartas constitutivas, mucho antes que fueran adicionados a nuestra Constitución Política. ${ }^{111}$

\section{CONCLUSIONES}

Primera. A casi doscientos años de haberse iniciado las relaciones políticas y diplomáticas entre México y Venezuela, solamente en una ocasión hubo ruptura de éstas y actualmente continúan en el nivel más bajo, con encargados de negocios al frente de las embajadas de ambos países.

Segunda. Las relaciones bilaterales y multilaterales donde ambos países han participado, se desarrollaron siempre en el campo de la cooperación mutua y en beneficio de los países vecinos de Centroamérica y el Caribe, como en el caso del Acuerdo de San José y del Grupo de Contadora, en donde venden petróleo a precios preferentes, y sobre todo, han fungido como mediadores para consolidar el proceso de paz en El Salvador, Guatemala y Nicaragua.

Tercera. El presidente Hugo Chávez se retiró del Grupo de los Tres, acuerdo comercial y de cooperación económica entre Colombia, Venezuela y México, bajo el argumento de que sus pares guían gobiernos neoliberales y van en contra del socialismo.

Cuarta. Resulta muy positivo que las relaciones diplomáticas entre México y Venezuela hayan mejorado, toda vez que ambos países son los mayores productores de petróleo en América Latina, y además forman

110 Diario Oficial de la Federación, 11 de mayo de 1988.

111 Cfr. Carta de las Naciones Unidas y Carta de los Estados Americanos, www.onu. org y www.oas.org. 
parte de varios acuerdos de cooperación en beneficio mutuo y de los países vecinos, toda vez que unidos se fortalecen para enfrentar las agresiones económicas de los Estados Unidos de América.

\section{BIBLIOGRAFÍA}

CARREÑO, Alberto María, La diplomacia extraordinaria entre México y Estados Unidos, México, Jus, 1951, t. I.

Cerutti GuldBerg, Horacio, "La utopía americana en el siglo XXI. ¿Utopía de la unidad o mitos de la integración?", Latinoamérica. Anuario de Estudios Latinoamericanos, núm. 34, México, UNAM, Centro Coordinador y Difusor de Estudios Latinoamericanos, 2002.

Collado Herrera, María del Carmen, Venezuela, una historia breve, México, Instituto de Investigaciones José María Luis Mora, 2000.

La Jornada, México, 10 y 14-17 de noviembre de 2005, y 19 de abril de 2006.

Diario Oficial de la Federación del 11 de mayo de 1988.

Declaración conjunta de los presidentes de Venezuela y México, San José de Costa Rica, 3 de agosto de 1980. www.presidenciadelarepu blica.gob.mx.

Flores OleA, Víctor, Relación de Contadora, México, Secretaría de Relaciones Exteriores-Fondo de Cultura Económica, 1988.

HELlER, Claude, "El Grupo de Contadora en la crisis centroamericana", en Secretaría de Relaciones Exteriores, Política exterior de México, 175 años de historia, México, SRE, 1985, t. III.

—_, "México designa a su nuevo embajador en Venezuela", La Jornada on line, México, 9 de agosto de 2007, www.lajornada.un am.mx.

LÓPEZ-PORTILlo TOSTADO, Felícitas (coord.), "La normalización de las relaciones con los países grancolombianos", Bajo el manto del Libertador. Colombia, Panamá y Venezuela 1821-2000, México, Secretaría de Relaciones Exteriores, 2004.

, "Venezuela, desde la cancillería mexicana: los años de la posguerra", Latinoamérica, Anuario de Estudios Latinoamericanos, México, UNAM, Centro Coordinador y Difusor de Estudios Latinoamericanos, núm. 30, 1998. 
MAdRID Hurtado, Miguel de la, "Palabras del presidente de los Estados Unidos Mexicanos al término de las segundas conversaciones con los presidentes de los países del Grupo de Contadora", en Secretaría de Relaciones Exteriores, Política exterior de México, Discursos y documentos, México, SRE, 1983.

MÉNDEZ REYES, Salvador, "De los antecedentes coloniales a la primera década del siglo XX", en LÓPEZ-PORTILLO TOSTADO, Felícitas (coord.), Bajo el manto del Libertador. Colombia, Panamá y Venezuela 1821-2000, Secretaría de Relaciones Exteriores, 2004.

MUÑOZ MATA, Laura, "De la retórica al 'fortalecimiento de lazos'. En busca de la cooperación 1960-2000”, en LÓPEZ-PORTILlo TOSTADO, Felícitas (coord.), Bajo el manto del Libertador. Colombia, Panamá y Venezuela 1821-2000, Secretaría de Relaciones Exteriores, 2004.

"Nombran nuevo embajador de Venezuela en México", Terra, 7 de agosto de 2007, www.terra.com.mx/politica.

PÉREZ REYES, Elda, "Manuel Aspíroz ante el bloqueo de los puertos venezolanos (1902-1903)", El Caribe entre México y los Estados Unidos, Morelia, Universidad Michoacana de San Nicolás de Hidalgo, Instituto de Investigaciones Históricas, 2005.

Presidencia de la República, "Se prorrogó el Acuerdo de San José", Actividades de la Presidencia de la República, Los Pinos, 4 de agosto de 2004, www.tlatoani.2004.presidencia.gob.mx/comunicados.

RAMíREZ DomínGUEZ, Kenneth, "Felipe Calderón confía en que relaciones diplomáticas con Cuba y Venezuela se normalizarán”, El Universal on line, México, 3 de junio de 2007.

RomÁn, José Antonio, "Nada oficial sobre normalización de relaciones con México: Lagonell”, La Jornada, México, miércoles 11 de julio de 2007.

Secretaría de Relaciones Exteriores, Política exterior de México, 175 años de historia, México, Archivo Histórico Diplomático Mexicano, 1985, ts. I-IV.

Secretaría Permanente del Sela, La nueva etapa de la integración regional, México, Sistema Económico Latinoamericano-Fondo de Cultura Económica, 1992.

SePÚlvedA AMOR, Bernardo, "Presentación", en Flores OleA, Víctor (ed.), Relación de Contadora, México, Fondo de Cultura Económica, 1988. 
VARGAS, María del Rocío, "La integración energética en América del Sur: La iniciativa de Petroamérica", Latinoamérica, Revista de Estudios Latinoamericanos, México, UNAM, Centro Coordinador y Difusor de Estudios Latinoamericanos, núm. 40, 2005. 